\title{
A comparison of the influence on plasma lipids and platelet function of supplements of $\omega \mathbf{3}$ and $\omega 6$ polyunsaturated fatty acids
}

\author{
BY T. A. B. SANDERS AND MICHELE C. HOCHLAND \\ Department of Nutrition, Queen Elizabeth College, University of London, \\ Campden Hill Road, London W8 7AH
}

(Received 16 December 1982-Accepted 14 June 1983)

\begin{abstract}
1. A randomized double-blind crossover trial was carried out to compare the influence on plasma lipid concentrations, platelet thromboxane $B_{2}$ production and platelet aggregation induced by ADP, collagen and U46619 (a prostaglandin endoperoxide analogue), of a daily $10 \mathrm{~g}$ supplement of a fish-oil concentrate (MaxEPA), which provided $(\mathrm{g}): 1 \cdot 720: 5 \omega 3,0 \cdot 322: 5 \omega 3$ and $1 \cdot 222: 6 \omega 3$, taken for 2 weeks by ten healthy subjects, with one of vegetable oil providing $3 \cdot 418: 2 \omega 6$.

2. A lower response to platelet aggregation induced by $0.5 \mu \mathrm{g}$ collagen $/ \mathrm{ml}$ but not by other aggregating agents was observed following both types of supplement. Platelet thromboxane $\mathrm{B}_{2}$ production induced by collagen also tended to be lower following the supplements.

3. Plasma total cholesterol concentrations were unaffected by the supplements. The MaxEPA but not the vegetable-oil supplement lowered the concentration of plasma triglycerides and increased that of high-density-lipoprotein-cholesterol.
\end{abstract}

It has been proposed that populations that eat large amounts of fish or marine mammals may be less prone to coronary heart disease because of their high intake of eicosapentaenoic

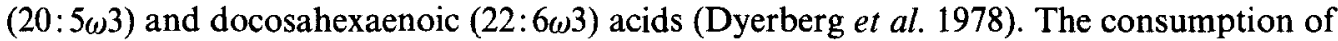
these polyunsaturated fatty acids, which are derived from marine oils, lowers plasma triglyceride concentrations and prolongs template bleeding time (Goodnight et al. 1981; Sanders et al. 1981). The results of a dose-response experiment using a fish-oil concentrate, MaxEPA (Sanders \& Roshanai, 1983), suggested that as little as 3-4 g 20:5 $\omega 3$ and 22:6 63 may lower plasma triglyceride concentrations.

Bleeding time is believed to reflect the capacity of platelets to make thromboxane $\mathrm{A}_{2}$ from

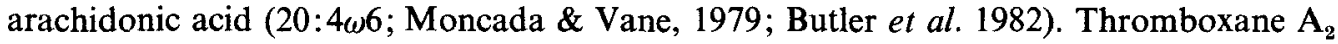
is a powerful vasoconstrictor and platelet aggregating agent. It has a very short half-life and rapidly hydrolyses to form the inactive thromboxane $B_{2}$. The measurement of the latter can, therefore, be used to measure thromboxane $A_{2}$ synthesis indirectly (Amezcua et al. 1979). Thromboxane $B_{2}$ production is inhibited in subjects consuming large amounts of oily fish (Siess et al. 1980; Sinclair, 1980). The prolonged bleeding time following the consumption of fish oil can be related to changes in platelet lipid composition and thromboxane $\mathrm{A}_{2}$ production: $20: 4 \omega 6$ is partially replaced in platelet lipids by $20: 5 \omega 3$ and $22: 6 \omega 3$.

Vegetable oils are rich sources of linoleic acid $(18: 2 \omega 6)$ but do not contain $20: 5 \omega 3$ and 22:6 63 . The consumption of these oils reduces the rate at which platelets aggregate in vivo (Hornstra et al. 1973; Fleischman et al. 1975) but does not prolong template bleeding time (Hornstra et al. 1973). This change occurs within a few days before changes in platelet composition have had time to take place.

Brox et al. (1981) reported that thromboxane $\mathrm{B}_{2}$ production and platelet aggregation induced by low doses of collagen were inhibited after 6 weeks of taking a daily $25 \mathrm{ml}$ supplement of either maize oil or cod-liver oil. However, the cod-liver oil contained a lower proportion of polyunsaturated fatty acids, mainly as $\mathrm{C}_{20-22} \omega 3$ fatty acids, compared with maize oil which provided mainly linoleic acid. The present study compares the influence 
on plasma lipids, platelet aggregation and thromboxane $\mathrm{B}_{2}$ production of supplements providing similar amounts but different types of polyunsaturated fatty acids.

\section{EXPERIMENTAL}

\section{Subjects, materials and methods}

The subjects of the present study were staff and students of Queen Elizabeth College. Consent was obtained from individuals and from the College Ethical Committee for all procedures. Subjects were free from any aspirin-containing medication for at least $10 \mathrm{~d}$ before any measurement of platelet function. Ten subjects (six male and four female, aged 22-35 years) were divided into two groups. The first group received a daily $10 \mathrm{~g}$ supplement of fish oil triglyceride concentrate (MaxEPA; Seven Seas Health Care Ltd, Hull) for 2 weeks. The second group received $10 \mathrm{~g}$ of a mixture of olive oil and maize oil daily for 2 weeks. During the subsequent 2 weeks the groups switched their dietary supplement. The investigation was carried out as a randomized double-blind crossover study.

The oils were administered in opaque soft gelatin capsules each containing $1 \mathrm{~g}$ oil. A peppermint flavour was used to disguise the contents of the capsule. The peppermint flavour used was natural peppermint oil (Mitcham type; Givaudan). It was added at a concentration of $2000 \mathrm{mg} / \mathrm{kg}$. Both oils contained additional DL-tocopherol acetate $(1000 \mathrm{mg} / \mathrm{kg})$, citric acid $(100 \mathrm{mg} / \mathrm{kg})$ and the antioxidant dodecyl gallate $(200 \mathrm{mg} / \mathrm{kg})$ and were provided by the Marfleet Refining Co., Hull. The fatty acid compositions of the two oils were determined by gas-liquid chromatography after conversion of the fatty acids to methyl esters (Sanders \& Younger, 1981).

Venous blood samples $(30 \mathrm{ml})$ were obtained with minimum venous occlusion from fasting subjects before and at the end of each treatment period. The weight of the subject was recorded on each occasion that blood was taken. Plasma lipid concentrations were determined as previously described (Sanders et al. 1981).

Platelet aggregation was studied by the turbidometric method of Born (1962) in citrated platelet-rich plasma (PRP) commencing $1 \mathrm{~h}$, and being completed inside $2 \mathrm{~h}$, after collection of the blood sample as described previously (Sanders et al. 1981; Sanders \& Roshanai, 1983). PRP was obtained from blood collected into a solution of $31.3 \mathrm{~g}$ of trisodium citrate $/ 1$ water $(9: 1, \mathrm{v} / \mathrm{v})$ after centrifugation $(120 \mathrm{~g}$ for $15 \mathrm{~min})$ at room temperature immediately after collecting the blood. Platelet-poor plasma (PPP) was prepared by centrifuging the remaining blood at $1500 \mathrm{~g}$ for $15 \mathrm{~min}$ at room temperature. PRP was adjusted to $250000 \mathrm{platelet} / \mu \mathrm{l}$ with autologous PPP. Platelet counts were made using a Coulter ZBI counter (Coulter Instruments, Luton, Beds.) fitted with a $70 \mu$ l orifice tube.

Platelet aggregation was studied using a Payton dual channel aggregometer (Payton Associates, Scarborough, Ontario). Portions of adjusted PRP and PPP $(0.5 \mathrm{ml})$ were stirred at $1000 \mathrm{rev} / \mathrm{min}$ at $37^{\circ}$ and transmitted light was adjusted at $90 \%$ for PPP and $10 \%$ for PRP. Portions of PRP $(0.5 \mathrm{ml})$ were preincubated without stirring for $4 \mathrm{~min}$ at $37^{\circ}$ and then transferred to the aggregometer and a stir bar added; after $1 \mathrm{~min}$ the aggregating agent was added and the response was recorded on a chart recorder. The response was taken to be the maximal change in light transmittance. Aggregation was induced by $2.0 \mu \mathrm{M}$-ADP (Sigma Chemical Co., Poole, Dorset), $1.5 \mu \mathrm{M}$-U46619 (a prostaglandin endoperoxide analogue; Upjohn Chemical Co. Kalamazoo, Michigan) and collagen (Hormon-Chemie, Munich West Germany) at 10,1 and $0.5 \mu \mathrm{g} / \mathrm{ml}$ PRP. ADP was used at a final concentration of $2.0 \mu \mathrm{M}$ because previous studies (Sanders et al. 1981) have found this dose approximates to the dose giving the half maximal response $\left(\mathrm{ED}_{50}\right)$. U46619 was dissolved in ethanol and stored at $4^{\circ}$; dilutions were made freshly each day with iso-osmotic saline $(8.9 \mathrm{~g}$ of sodium chloride/l of water). Preliminary studies showed that this was the minimal dose to result in maximal aggregation. 
Table 1. Fatty acid composition $(\mathrm{g} / \mathrm{kg})$ of the two oils given to the subjects

\begin{tabular}{lrc}
\hline Fatty acid & $\begin{array}{c}\text { Fish-oil } \\
\text { concentrate, } \\
\text { MaxEPA }\end{array}$ & $\begin{array}{c}\text { Vegetable } \\
\text { oil }\end{array}$ \\
\hline $14: 0$ & 65 & - \\
$14: 1$ & 9 & - \\
$16: 0$ & 144 & 121 \\
$16: 1+17: 0$ & 91 & 11 \\
$18: 0$ & 45 & 22 \\
$18: 1$ & 147 & 427 \\
$18: 2 \omega 6$ & 38 & 359 \\
$18: 3 \omega 3+20: 1$ & 35 & 13 \\
$22: 0+20: 2$ & 27 & - \\
$22: 1+20: 3 \omega 6$ & 22 & - \\
$20: 3 \omega 3+20: 4 \omega 6$ & 13 & - \\
$20: 5 \omega 3$ & 182 & - \\
$22: 4$ & 18 & - \\
$22: 5 \omega 3$ & 32 & - \\
$22: 6 \omega 3$ & 128 & - \\
\hline
\end{tabular}

Thromboxane $\mathrm{B}_{2}$ production by platelets stimulated with collagen was determined as follows. Portions of PRP $(50 \mu \mathrm{l})$ were withdrawn from the aggregometer cuvette $4 \mathrm{~min}$ after the addition of the collagen reagent and added to $950 \mu 150 \mathrm{~mm}$-Tris buffer $(\mathrm{pH} 7.5)$ containing imidazole $(500 \mu \mathrm{g} / \mathrm{ml})$, mixed and immediately frozen in liquid nitrogen. These samples were stored at $-22^{\circ}$ until analysed. Thromboxane $B_{2}$ was determined by radioimmunoassay using a similar protocol to that described for the assay of 6-keto-prostaglandin $F_{1-\alpha}$ (Salmon, 1978). Antibody thromboxane $B_{2}$ (Wellcome Laboratories, Beckenham, Kent) and $\mathrm{H}^{3}$-labelled thromboxane tracer were obtained through New England Nuclear (Southampton, Hants).

A paired sample $t$ test or, if conditions for its use were not valid, Wilcoxon's test were used for the comparison of results between treatment periods. A two-sample $t$ test or, if this was not appropriate, a Mann-Whitney test was used to test for differences between treatments.

\section{RESULTS}

Table 1 shows the fatty acid compositions of the two oils. Both oils contained a similar proportion of polyunsaturated fatty acids but the type of polyunsaturated fatty acids provided was different. The MaxEPA supplement provided $(\mathrm{g}): 1 \cdot 720: 5 \omega 3,0 \cdot 322: 5 \omega 3$ and $1 \cdot 222: 6 \omega 3$ and the vegetable-oil supplement provided 3.4 18:2 $\omega 6$. Unlike cod-liver oil and many other fish oils, MaxEPA contained only small amounts of $\mathrm{C}_{20-22}$ monoenes. According to the manufacturers, MaxEPA contained negligible amounts of vitamin D and considerably less vitamin A than cod-liver oil.

Body-weight and total plasma cholesterol concentration were not influenced by the supplement (Table 2). The concentration of high-density-lipoprotein (HDL)-cholesterol increased following the MaxEPA supplement independently of the order of treatment. In the group that received the MaxEPA treatment first, the concentration of HDL-cholesterol did not fall when they switched to the vegetable-oil supplement. The response of the plasma triglycerides differed between vegetable oil and MaxEPA treatments. Plasma triglyceride concentrations fell, markedly in some cases, following the administration of MaxEPA.

There were no significant differences between treatments in response to platelet aggregation induced by ADP, U46619 and collagen at $10 \mu \mathrm{g} / \mathrm{ml}$ PRP (Table 3). However, the response to aggregation induced by $0.5 \mu \mathrm{g}$ collagen/ml PRP was lower following the supplements. 


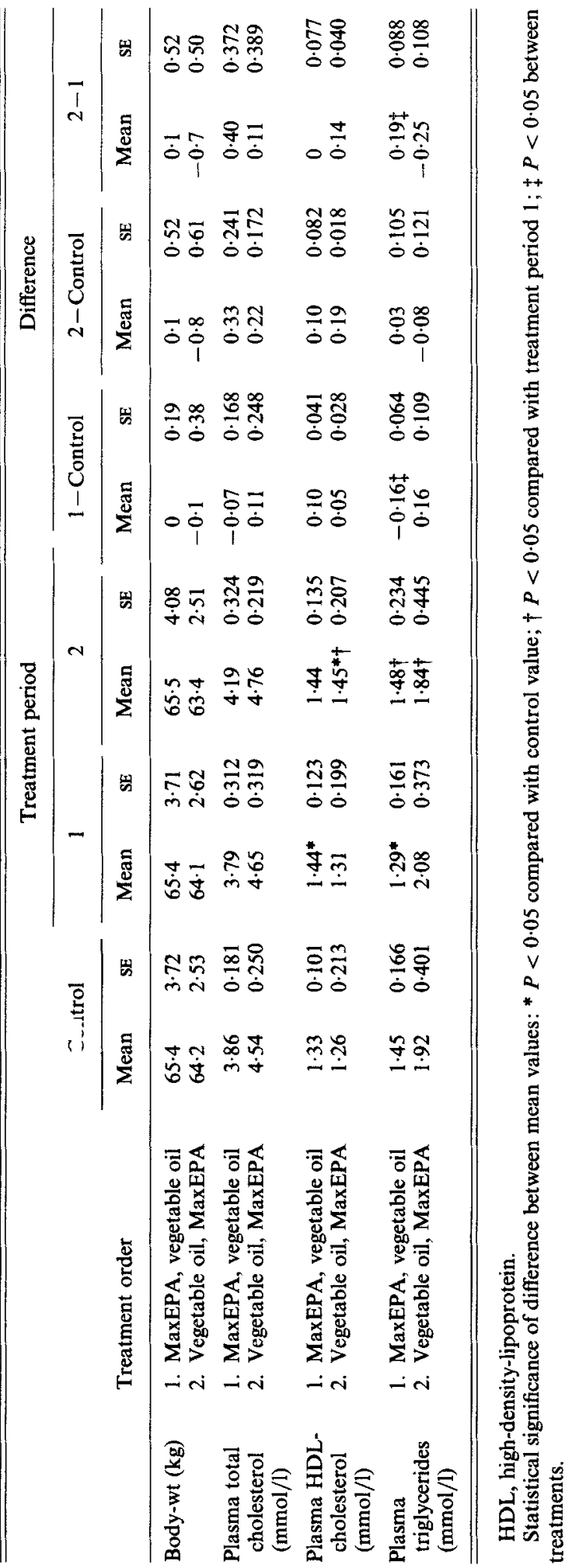


בับ

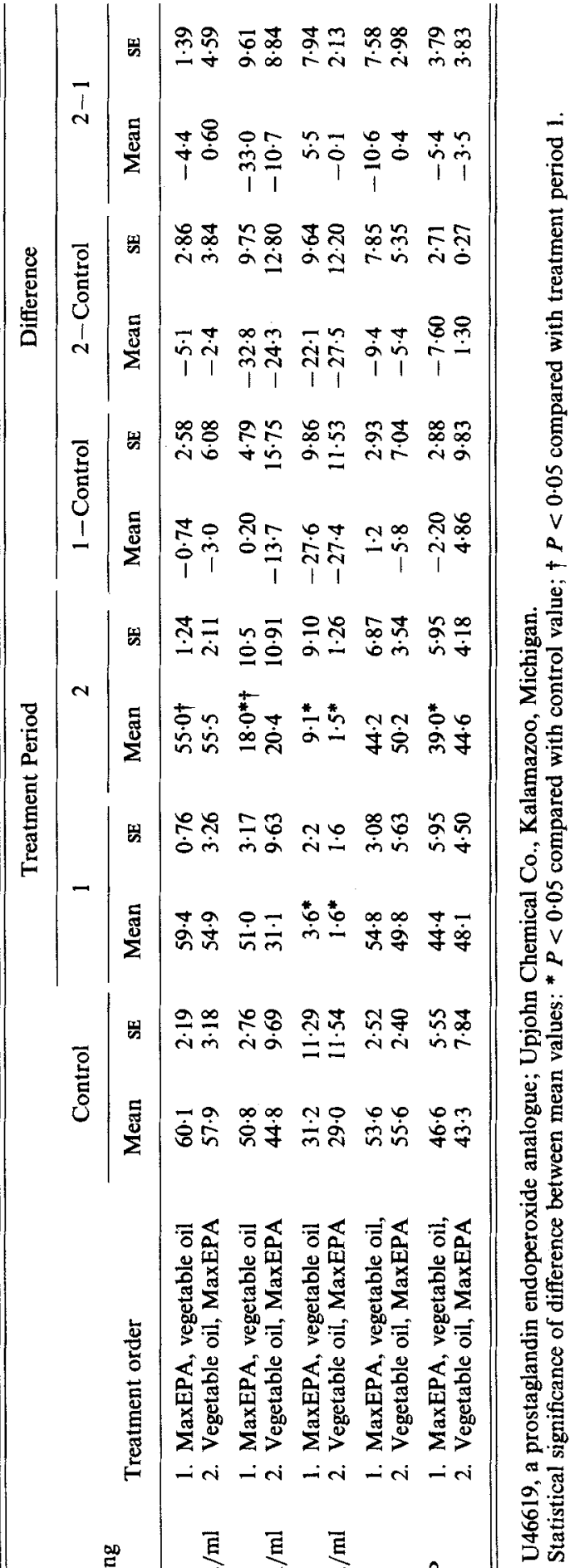


The response to aggregation induced by $1 \mu \mathrm{g}$ collagen/ml PRP was lower on the vegetable-oil than on the MaxEPA supplement. Thromboxane $\mathrm{B}_{2}$ production was greatest when induced by $10 \mu \mathrm{g}$ collagen/ml PRP but was lower following the supplements (Table 4). Thromboxane $B_{2}$ production stimulated by 1 and $0.5 \mu \mathrm{g}$ collagen $/ \mathrm{ml}$ PRP also tended to be lower following the supplements. However, these differences were only statistically significant in the group that received MaxEPA first.

\section{DISCUSSION}

Our MaxEPA supplement provided considerably more $20: 5 \omega 3$ and 22:6 63 fatty acids than the $0.3 \mathrm{~g}$ in British diets (Doyle et al. 1983) but much less than the $11 \mathrm{~g}$ found in the diets of Greenland Eskimos (Bang \& Dyerberg, 1980). The intake was of a similar order to the amount provided by the diets of Japanese fishermen (Hirai et al. 1980). The typical British diet provides a daily intake of linoleic acid $(18: 2 \omega 6)$ in excess of $9 \mathrm{~g}$ (Burt et al. 1983). Therefore, the vegetable-oil supplement probably substantially increased the daily intake of linoleic acid by the subjects.

We chose to feed our subjects the supplements for 2-week periods because the life-span of platelets is in the order of 7-10 d and because previous studies (Von Lossonczy et al. 1978; Sanders \& Roshanai, 1983) have shown that it is possible to produce changes in plasma lipid concentrations and platelet fatty acid composition inside this period.

The platelet aggregating agents used in the present study were chosen because platelet aggregation induced by them is inhibited by the addition of 20:5 3 in vitro (Gryglewski et al. 1979; Jakubowski \& Ardlie, 1979). A similar inhibitory effect on platelet aggregation can be observed following the addition of $22: 6 \omega 3$ (T. A. B. Sanders and N. Bolster, unpublished results). Aggregation can be induced by ADP, U46619 and $10 \mu \mathrm{g}$ collagen $/ \mathrm{ml}$ PRP when prostaglandin formation is inhibited by drugs, whereas platelet aggregation induced by collagen at 1 and $0.5 \mu \mathrm{g} / \mathrm{ml}$ does not occur if prostaglandin formation is inhibited (Sack \& Quiroga, 1976; Amezcua et al. 1979).

Kobayashi et al. (1981) showed that a fish-oil supplement providing $1.4 \mathrm{~g} \mathrm{20:5 \omega 3}$ and an unspecified amount of 22:6 63 taken daily for 4 weeks by Japanese subjects lowered whole blood viscosity. It was suggested that this reflected a change in platelet stickiness. Hirai et al. (1982) showed that platelet aggregation induced by $1 \mu \mathrm{g}$ collagen $/ \mathrm{ml}$ PRP was lowered after 2 and 4 weeks of consuming the same fish-oil supplement. Aggregation induced by $2 \mu \mathrm{M}$-ADP also tended to be lower. On the other hand, Sanders et al. (1981) found an increased maximal response for aggregation induced by ADP in subjects that had been given a daily $20 \mathrm{ml}$ cod-liver oil supplement for 6 weeks but bleeding time was paradoxically prolonged. Sanders \& Roshanai (1983) could show no influence in platelet aggregation induced by collagen at 10,2 and $1 \mu \mathrm{g} / \mathrm{ml}$ in subjects who had taken a daily supplement of 10 or $20 \mathrm{~g}$ of MaxEPA for 3 weeks. Our results for platelet aggregation are perplexing. Both supplements inhibited aggregation induced by $0.5 \mu \mathrm{g}$ collagen $/ \mathrm{ml}$ PRP but had no influence on aggregation induced by ADP, U46619 or $10 \mu \mathrm{g}$ collagen $/ \mathrm{ml} \mathrm{PRP}$. The vegetable-oil supplement decreased the response to aggregation induced by $1 \mu \mathrm{g}$ collagen $/ \mathrm{ml}$ PRP but this did not correlate with a reduction in thromboxane $\mathbf{B}_{2}$ production. This would suggest that the vegetable-oil supplement influenced platelet aggregation by a different mechanism, possibly one involving platelet activating factor. Thromboxane $\mathbf{B}_{\mathbf{2}}$ production was greatest at $10 \mu \mathrm{g}$ collagen/ml PRP which would support the view proposed by Butler et al. (1982) that the main function of thromboxane $A_{2}$ is as a vasoconstrictor rather than an aggregating agent. Although thromboxane $B_{2}$ production was significantly reduced in the group that received the MaxEPA first, there was a tendency for thromboxane $\mathbf{B}_{2}$ production to be lower after both types of supplements compared with the control period. It is possible that these changes were fortuitous or that a common component in the oil, 
possibly the peppermint flavour, influenced the results. Further studies should use an untreated group of subjects as controls.

The ability of MaxEPA to lower plasma triglyceride concentrations and to increase HDL-cholesterol concentrations confirms the observations of Sanders \& Roshanai (1983) and is in agreement with other studies using cod-liver oil (Sanders et al. 1981). It is also noteworthy that neither supplements influenced the concentration of total plasma cholesterol. The MaxEPA supplement provided an equivalent amount of 20:5 33 and 22: $6 \omega 3$ to that found in about $200 \mathrm{~g}$ mackerel (Paul \& Southgate, 1978). Von Lossonczy et al. (1978) showed that the consumption of this amount of mackerel daily led to a marked reduction in plasma triglyceride very-low-density-lipoprotein (VLDL) concentrations and a slight increase in HDL-cholesterol after 2 weeks. The failure of the vegetable-oil supplement to lower plasma triglyceride concentrations is in agreement with Goodnight et al. (1982) and Kraemer et al. (1982). Moreover, a daily supplement of $20 \mathrm{ml}$ linseed oil, which is rich in linolenic acid $(18: 3 \omega 3)$, similarly did not lower plasma triglyceride concentrations (Sanders \& Roshanai, 1983) thus implying that only the $\mathrm{C}_{20-22} \omega 3$ fatty acids show this effect. The mechanism for this triglyceride lowering effect is obscure. However, the clearance of triglycerides from plasma is increased in subjects who had consumed large amounts of salmon oil (Goodnight et al. 1982). The use of MaxEPA in the treatment of hypertriglyceridaemia associated with elevated VLDL concentrations deserves a controlled trial.

The authors are grateful to Dr J. Pike of the Upjohn Chemical Co. for the U46619, Dr J. Salmon of Wellcome Laboratories for the antiserum to thromboxane $\mathrm{B}_{2}, \mathrm{Mr} \mathrm{N}$. R. Bolster for his technical assistance and to the Marfleet Refining Co. for a grant.

\section{REFERENCES}

Amezcua, J. L., O'Grady, J., Salmon, J. A. \& Moncada, S. (1979). Thrombosis Research 16, 69-79.

Bang, H. O. \& Dyerberg, J. (1980). In Advances in Nutrition Research, vol 3., p. 1 [H. H. Draper, editor]. New York: Plenum Press.

Born, G. V. R. (1962). Nature 194, 927-929.

Brox, J. H., Killie, J.-E., Gunnes, S. \& Nordoy, A. (1981). Thrombosis and Haemostasis (Stuttgart) 46, 604-611. Burt, R., Buss, D. H. \& Kirk, R. S. (1983). Proceedings of the Nutrition Society 42, 71 A.

Butler, K. D., Maguire, E. D., Smith, J. R., Turnbull, A. A., Wallis, R. B. \& White, A. M. (1982). Thrombosis and Haemostasis (Stuttgart) 47, 46-82.

Doyle, W., Hare, W. R. \& Crawford, M. A. (1983). Proceedings of the Nutrition Society 42, 69A.

Dyerberg, J., Bang, H. O., Stoffersen, E., Moncada, S. \& Vane, J. R. (1978). Lancet ii, 117-119.

Fleischman, A. I., Justice, D., Bierrenbaum, M. L., Stier, A. \& Sullivan A. (1975). Journal of Nutrition 105, 1286-1290.

Goodnight, S. H., Harris, W. S. \& Connor, W. E. (1981). Blood 58, 880-885.

Goodnight, S. H., Harris, W. S., Connor, W. E. \& Illingworth, D. R. (1982). Arteriosclerosis 2, 87-113.

Gryglewski, R. J., Salmon, J. A., Ubatuba, F. B., Weatherley, B. C., Moncada, S. \& Vane, J. R. (1979). Prostaglandins 18, 453-478.

Hirai, A., Hamazaki, T., Terano, T., Nishikawa, T., Tamura, Y., Kumagai, A. \& Sajiki, J. (1980). Lancet ii, $1132-1133$.

Hirai, A., Terano, T., Hamazaki, T., Sajiki, J., Kondo, S., Ozawa, A., Fujita, T., Miyaoto, T., Tamura, Y. \& Kumagai, A. (1982). Thrombosis Research 28, 285-298.

Hornstra, G., Lewis, B., Chait, A., Turpeinen, O., Karvonen, M. S. \& Vergroesen, A. J. (1973). Lancet i, $1155-1157$.

Jakubowski, J. A. \& Ardlie, N. G. (1979). Thrombosis Research 16, 205-217.

Kobayashi, S., Hirai, A., Terano, T., Hamazaki, T, Tamura, Y. \& Kumagai, A. (1981). Lancet ii, 197.

Kraemer, F. B., Greenfield, M., Tobey, T. A. \& Reaven, M. (1982). British Journal of Nutrition 47, $259-288$.

Moncada, S. \& Vane, J. R. (1979). New England Journal of Medicine 300, 1142-1147.

Paul, A. A. \& Southgate, D. A. T. (1978). McCance and Widdowson's The Composition of Foods, 4th ed, MRC special report no. 297. London: H.M. Stationery Office.

Sack, E. S. \& Quiroga, E. (1976). Thrombosis and Haemostasis (Stuttgart) 35, 658.

Salmon, J. A. (1978). Prostaglandins 15, 382-397.

Sanders, T. A. B. \& Roshanai, F. (1983). Clinical Science 64, 91 -99. 
Sanders, T. A. B., Vickers, M. \& Haines, A. P. (1981). Clinical Science 61, 317-324.

Sanders, T. A. B. \& Younger, K. M. (1981). British Journal of Nutrition 45, 613-616.

Siess, W., Scherer, B., Bohlig, B., Roth, P., Kurzman, I. \& Weber, P. C. (1980). Lancet i, 441-444.

Sinclair, H. M. (1980). In Drugs Affecting Lipid Metabolism, pp. 363-370. [R. Fumagalli, D. Kritchevsky \& R. Paoletti, editors]. Amsterdam: Elsevier/North Holland Biomedical Press.

Von Lossonczy, T. O., Ruiter, A., Bronsgeest-Schoute, H. C., Van Gent, C. M. \& Hermus, R. J. (1978). American Journal of Clinical Nutrition 31, 1340-1346. 